\title{
Correspondence
}

\section{The real cost of waiting in a prison for a hospital psychiatric bed}

Forrester et al's study on the delays in hospital transfer from prison focuses on an important clinical issue, given it is common knowledge that there is a shortage of secure beds in the country. ${ }^{1}$

The recently published, government commissioned Bradley report ${ }^{2}$ recommended that the Department of Health should develop a new minimum target for the National Health Service (NHS) of 14 days to transfer a prisoner with acute, severe mental illness to an appropriate healthcare setting. There are plans to include the minimum waiting time in the local mental health contracts for prisons. The study highlights an important issue of prisoners remaining in inappropriate environments while waiting for a transfer. In prison settings, without the protection of the Mental Health Act, it is difficult to justify using the Mental Capacity Act 2005 to treat a mentally ill individual repeatedly.

The study calculates, based on unit costs, ${ }^{3}$ the 'saving' to the NHS of $€ 6.759$ million. Although this ballpark figure is a good starting point, the true costs to the NHS as a result of delayed transfers may well be higher based on the following factors.

The longer the patient remains in prison the longer their psychosis remains untreated. Marshall et $a l^{4}$ concluded in their systematic review that a longer period of untreated psychosis was associated with more severe overall symptoms, depression/anxiety, negative and positive symptoms, and worse overall function. Furthermore, people with longer duration of untreated psychosis were less likely to experience remission at 6,12 or 24 months. We suggest that 'delayed transfer patients' could have longer in-patient stays and require higher levels and more frequent episodes of observation, due to the higher degree of their mental disorder, thereby potentially increasing the costs to the NHS.

The other potentially significant effect of delayed transfers is escalation of self-injurious behaviour and risk to others, in the context of deteriorating mental health. Arguably, the escalation of risk behaviours may result in some prisoners eventually requiring placement in higher levels of security than if they had been transferred earlier in their illness. The evidence for this is reflected by higher prevalence of constant watch, higher incidence of the use of safer cells, care and separation units and transfers to general hospital for treatment. They are also seen more frequently in clinics by visiting psychiatrists and mental health in-reach teams. This increases the demand on meagre resources and arguably increases the overall cost of patient care.

The apparent initial 'savings' made from prisoners waiting to be transferred are negated by clinical and financial costs to the NHS in the long term. Finally, from the perspective of equivalence, prisoners should have the same timely access to appropriate mental health services as mentally disordered individuals in the community.
1 Forrester A, Henderson C, Wilson S, Cumming I, Spyrou M, Parrott J. A suitable waiting room? Hospital transfer outcomes and delays from two London prisons. Psychiatr Bull 2009; 33: 409-12.

2 Lord Bradley. Lord Bradley's Review of People with Mental Health Problems or Learning Disabilities in the Criminal Justice System. Department of Health, 2009

3 Department of Health. National Schedule of Reference Costs 2006-07 for NHS Trusts. Department of Health, 2008 (http://www.dh.gov.uk/en/ Publicationsandstatistics/Publications/PublicationsPolicyAndGuidance/ DH_082571).

4 Marshall M, Lewis S, Lockwood A, Drake R, Jones P, Croudace T. Association between duration of untreated psychosis and outcome in cohorts of first-episode patients : a systematic review. Arch Gen Psychiatry 2005; 62: 975-83.

Pratish B.Thakkar is ST6 in Forensic Psychiatry, Tees, Esk and Wear Valley NHS Trust, and Ranjit Kini and Phillip Brown are Consultant Forensic Psychiatrists. Email: pratish.thakkar@tewv.nhs.uk

doi: $10.1192 / \mathrm{pb} .34 .2 .71$

\section{First things first}

Recruiting psychiatrists is indeed a Sisyphean task. ${ }^{1}$ To counter this, the Royal College of Psychiatrists aims to engage more closely with college students. However, there seem to be more fundamental problems which need addressing.

The College wants to ensure that medical students are aware of the advantages of a career in psychiatry. Before we can do that, however, we have to first make careers in psychiatry more attractive. Although the intellectual stimulation and the challenges that psychiatry brings, the working environment, the increasing confusion about the role of psychiatrists, the current state and future of psychiatry, New Ways of Working and the continuous dismissal of psychiatry as a scientific field by the spin doctors and political gurus are areas of concern.

Compared with other fields, such as general practice, providing better and more flexible working environments in psychiatry does not seem to be part of the government's plan for the future of the National Health Service. ${ }^{2}$ Most of the agendas that are damaging the reputation of psychiatry and allowing people to question its scientific credentials are politically driven, but senior psychiatrists are also to blame for colluding with politicians and not doing enough to preserve the integrity of the field. ${ }^{3}$

Training opportunities for junior trainees are being compromised by replacing out-of-hour on-call rotas with other mental health professionals, purely to cut costs. Many trainees are struggling to get decent supervision, while some senior psychiatrists are too busy training nurse prescribers. There is nothing wrong with training other professionals but we need to get our priorities right. While the College and schools of psychiatry encourage higher trainees to get involved in medical education and recruit medical students, and there are many highly enthusiastic trainees willing to do this, the reality is that New Ways of Working and the new training schemes provide very little opportunity and time for the trainees to undertake any such activities. 
While we must continue to encourage people to join the most fascinating field of medicine, we also need to get our house in order.

1 Brown N, Vassilas CA, Oakley C. Recruiting psychiatrists - a Sisyphean task? Psychiatr Bull 2009; 33: 390-2.

2 Lord Darzi. High Quality Care for All: NHS Next Stage Review Final Report. TSO (The Stationery Office), 2008.

3 Craddock N, Antebi D, Attenburrow M-J, Bailey A, Carson A, Cowen P, et al. Wake-up call for British psychiatry. Br J Psychiatry 2008; 193: 6-9.

Salman A. Mushtaq is a Specialty Registrar, South Essex Partnership NHS Foundation Trust and Rengaraja M. Muthuveeran is a Specialty Doctor in Psychiatry, crisis resolution home treatment team, South Essex Partnership NHS Foundation Trust. Email: Salman.Mushtaq@southessex-trust.nhs.uk

doi: 10.1192/pb.34.2.71a

\section{Are psychiatrists natural leaders?}

Professor Buckley is arguing for training in leadership skills for psychiatrists. ${ }^{1}$ He has not, however, made an obvious distinction between leadership and management, although they can be considered two separate attributes. Management is more of the here and now, the day-to-day stuff, the efforts to keep the wheels moving, as opposed to leadership which involves almost designing a new or better set of wheels. Leadership is about the future - the ability in some ways to be able to look into the crystal ball, get others to look too and somehow achieve that vision. Leadership is much more challenging, although day-to-day management looks as if there are no more challenges left. Leadership is, of course, much more satisfying.

There is also an argument whether leaders are born or can be made. Is the US president, Barack Obama, a born leader or is he a product of the PR gurus working overtime? Were Mandela or Gandhi born leaders or just born into a situation that made them leaders?

It is even more difficult to argue that psychiatrists are natural leaders. In our profession it is usually said that we need 'good communication skills' - every candidate for a post in psychiatry will put this down as one of their attributes. But what does this mean? What communication skills are we talking about? When we are training, the non-verbal communication is always pointed out as an important part of assessment. When we talk about communication, do we mean listening skills too? Are well-known world leaders good listeners as well? Or do we identify them more with their oratory skills?

It is a myth to think psychiatrists are natural leaders. We must not delude ourselves in thinking so. If anything, we just about match up to the rest of the medical profession. We have had good leaders in psychiatry, but we need better ones. It almost looks as if we need to make some, they are not born these days.

1 Buckley PF. Leadership development: more than on-the-job training. Psychiatr Bull 2009; 33: 401-3.

Vishal Agrawal is Consultant Psychiatrist and Clinical Director, South Essex Partnership University NHS Foundation Trust. Email: vishal.agrawal@southessex-trust.nhs.uk

doi: $10.1192 / \mathrm{pb} .34 .2 .72$

\section{Doctor's ethnicity also matters}

Nilforooshan et al recently examined the rates and outcome of appeal against detention under the Mental Health Act 1983 for different ethnic groups. They found that Black Caribbean and White Irish groups, although lodging significantly more appeals compared with other ethnic groups (at $63 \%$ and $68 \%$ respectively compared with $39 \%$ White British), were underrepresented in the group of patients who successfully had their detention discharged. These findings are revealing, but they would have been more useful if the ethnicity of the tribunal members overseeing the appeal had also been taken into account.

The 2005 Census by the Royal College of Psychiatrists ${ }^{2}$ reveals the ethnic breakdown of British psychiatrists by grade and highlights the increasing ethnic diversity of psychiatrists in Britain today. Morgan \& Beerstecher ${ }^{3}$ recently studied general practitioners' practices and found that ethnic minority patients tend to be cared for by ethnic minority doctors. Hence any analysis of the impact of ethnicity on the individual treatment of a patient and of the system of care as a whole would be incomplete and potentially flawed without the inclusion of the ethnicity of the professionals involved. In the decades-old debate on the institutional racism of mental health services, the trend so far has been to assume by default that psychiatrists are ethnically or culturally White British. It is important that future studies take into consideration the evolution of the workforce in terms of ethnicity, but also gender and social class.

1 Nilforooshan R, Amin R, Warner J. Ethnicity and outcome of appeal after detention under the Mental Health Act 1983. Psychiatr Bull 2009; 33: 288-90.

2 Royal College of Psychiatrists. Annual Census of Psychiatric Staffing 2005. Royal College of Psychiatrists, 2005 (http://www.rcpsych.ac.uk/pdf/ Census\%20results\%20-\%202005.pdf).

3 Morgan C, Beerstecher HJ. Ethnic group and medical care: what about doctor factors? [letter] BMJ 2009; 339: b4060.

Chiara A. Solari is ST1 in Psychiatry and Joseph El-Khoury is ST6 in Adult Psychiatry, Oxfordshire and Buckinghamshire Mental Health NHS Foundation Trust. Email: chiara.solari@obmh.nhs.uk

doi: $10.1192 / p b .34 .2 .72 a$

\section{WPBA or CASC/OSCE: where is it going wrong?}

I have been involved in all aspects of training and workplacebased assessment (WPBA) as a consultant, chair of annual review of competence progression panels and a Royal College of Psychiatrists' examiner for the past 6 years, and experience the problems discussed by Menon et al and commentators ${ }^{2,3}$ regularly. The inherent weaknesses of WPBAs have been well documented in these studies, but one also needs to seriously consider why trainees who are proclaimed as competent in clinical skills (as evidenced by successful WBPAs) are performing so poorly at the College's Clinical Assessment of Skills and Competences (CASC) exam, where the success rate has dropped to less than a third?

As an examiner, I sometimes have been exasperated at the poor standards of performance in the recent CASCs where problems have been evident in all aspects of clinical and communication skills (knowing, knowing how, showing how and doing). Is that a reflection of failure of training systems and 